BMJ Open Sport \& Exercise Medicine

\title{
Bicycling-related concussions leading to postconcussion syndrome in adults
}

\author{
Connor Moore (D , ${ }^{1}$ Paria Baharikhoob, ${ }^{1,2}$ Mozhgan Khodadadi, ${ }^{1}$ Charles H Tator ${ }^{1,3}$
}

To cite: Moore C, Baharikhoob P, Khodadadi M, et al. Bicycling-related concussions leading to postconcussion syndrome in adults. BMJ Open Sport \& Exercise Medicine 2020;6:e000746. doi:10.1136/ bmjsem-2020-000746

Accepted 15 March 2020

\section{Check for updates}

(c) Author(s) (or their employer(s)) 2020. Re-use permitted under CC BY-NC. No commercial re-use. See rights and permissions. Published by BMJ.

${ }^{1}$ Canadian Concussion Centre, Toronto Western Hospital, Toronto, Ontario, Canada ${ }^{2}$ Institute of Medical Science, Faculty of Medicine, University of Toronto, Toronto, Ontario, Canada

${ }^{3}$ Division of Neurosurgery, Toronto Western Hospital and University of Toronto, Toronto, Ontario, Canada

Correspondence to Dr Charles H Tator; Charles.Tator@uhn.ca

\section{ABSTRACT}

Background Concussions among adult bicyclists are common, but little is known about the long-term effects of the consequences of these concussions such as postconcussion syndrome (PCS) including its occurrence, clinical features and recovery potential. Indeed, our study is the first to examine PCS due to bicycling in any age group.

Objectives We examined patient demographics, concussion mechanisms and persistent symptoms as factors leading to PCS in adults and the potential for recovery.

Methods We conducted a retrospective chart review of 28 patients age 18 or older who sustained a concussion while bicycling and were referred to the Canadian Concussion Centre for management of PCS.

Results Eighteen patients (64.3\%) fell from their bicycles due to loss of control, attempts to avoid a crash or collision with an object. Eight patients $(28.6 \%)$ were struck by a motor vehicle, and two patients (7.1\%) were injured by collision with another bicycle. The mean duration of PCS was 23.7 months and at the time of the last follow-up, 23 $(82.1 \%)$ patients had failed to recover completely. Patients with one or more previous concussions had a significantly longer duration of PCS ( $p=0.042)$. Bicycling concussions resulted in a greater mean duration of PCS (23.7 months) than a comparison group of patients with PCS due to collision sports (16.1 months) ( $p=0.07)$.

Conclusion Adults who sustain bicycling-related concussions and develop PCS often have long-lasting symptoms; greater attention should be given to prevention strategies such as improved bicycling infrastructure and safer bicycling practices to reduce concussions in adult bicyclists.

\section{INTRODUCTION}

Bicycling, as a form of transportation and recreation is popular, and has been steadily increasing in Canada, with an estimated 7.0 million people having bicycled in a 3-month period in 2013/2014. ${ }^{1}$ In the senior author's study of catastrophic injuries in sports and recreation in Ontario from 1986 to 1995 , bicycling ranked very high as a cause of catastrophic injury. Indeed, almost half of the bicycling injuries were brain injuries, of which one-third were fatal. ${ }^{2}$ Between 1994 and 2012, 1408 fatalities were reported in Canada due to bicycling-related incidents. ${ }^{3}$

\section{What are the findings?}

Lost control of the bicycle and fell $(35.7 \%)$, struck by a motor vehicle $(28.6 \%)$, tried to avoid striking a person or animal and lost control (14.3\%), collided with an object (14.3\%) and injured as a result of a collision with another bicycle $(7.1 \%)$ were the mechanisms of concussion.

- The most prevalent symptoms were headache $(71.4 \%)$, fatigue $(53.6 \%)$, memory problems $(50.0 \%)$, sleep disturbance $(50.0 \%)$, anxiety $(46.4 \%)$ and sensitivity to light/noise (46.4\%).

- Bicycling concussions resulted in a greater duration of postconcussion syndrome (23.7 months) compared with a collision sports comparison group (16.1 months).

At the time of the last follow-up, $23(82.1 \%)$ patients had failed to recover completely.

How might it impact clinical practice in the future?

These findings help to elucidate the manifestation of postconcussion syndrome (PCS) following bicyclingrelated concussion and can assist clinicians in the management of such sports-related injuries.

- Inform clinicians about the severity of bicyclingrelated concussions and subsequent PCS, and potential prevention measures.

Compared with motor vehicle occupants, bicyclists are more vulnerable road users, and are up to 10 times more likely to be injured per kilometre travelled. Head injuries were responsible for about $30 \%$ of hospital admissions for bicycling-related injuries and over $75 \%$ of cycling deaths. ${ }^{4}$ Studies have reported significant differences in the incidence of postconcussion syndrome (PCS) following concussion, with estimates ranging from $5 \%$ to $58 \% .{ }^{56}$ The most commonly reported incidence of PCS is $10 \%-15 \% .^{7-9}$ Approximately $80 \%-90 \%$ of concussions are short term, with symptoms dissipating within about 28 days of injury. In contrast, those with PCS experience symptoms such as headache, dizziness, fatigue, irritability, cognitive difficulty, depression, anxiety and/or sleep disturbance for a 
prolonged period. Indeed, these symptoms can persist for months to years after injury, leading to long-term disability. ${ }^{10-12}$ In the present study, PCS was defined as one or more concussion symptoms which persisted for longer than 3 months. ${ }^{13}$

The cost to society associated with preventable injuries is an estimated $\$ 26.8$ billion per year in Canada. ${ }^{14}$ Moreover, the physical, cognitive and neurobehavioural repercussions of PCS account for substantial impairment which, in turn, impedes the ability of individuals with PCS to return to school, work or play. ${ }^{15}$ This reduces the health-related quality of life of the injured and the family members who care for them. ${ }^{1617}$

Previous studies have examined the factors influencing the prevalence of head injury and associated outcomes following bicycling-related accidents. ${ }^{18-20}$ However, the majority included patients ranging from paediatric to adult age. Also, previous concussion studies from our centre have analysed the demographics, clinical features and predictors associated with PCS, including the analysis of sports-related PCS in all age groups. ${ }^{21} 22$ In contrast, the present study is the first to focus specifically on PCS following bicycling-related concussion, and the first to exclusively examine concussion in an adult population of bicyclists. The objective was to investigate the main factors that contribute to the occurrence and duration of PCS in adults after bicycling-related concussions. We examined the patient characteristics, injury mechanisms, radiographic findings, symptomatology and recovery after bicycling-related PCS in patients referred to the Canadian Concussion Centre (CCC) over a 10-year period.

\section{MATERIALS AND METHODS Study design}

This is a longitudinal observational study of all adult patients age 18 and older with bicycling-related PCS referred to the CCC at the Toronto Western Hospital between 2008 and 2018. During this period, 851 patients with concussions were referred to one of the authors (CHT) at the Concussion Clinic of the CCC of which 39 sustained a concussion as a result of a bicycling-related injury and had symptoms lasting more than 3 months. Eleven of the 39 patients were subsequently excluded from the study: four who proved to have more severe brain injuries than concussion; three who were under the age of 18; three due to missing information, including the exact mechanism of injury and associated symptoms and one due to the coexistence of a brain tumour. The remaining 28 patients were included in the study (figure 1). For comparison, we selected an adult group of 86 patients from the CCC records who sustained a concussion while playing a collision sport.

\section{Data collection}

The information collected included patient characteristics (sex, age, previous concussions and pre-existing conditions), helmet use during the bicycling incident,

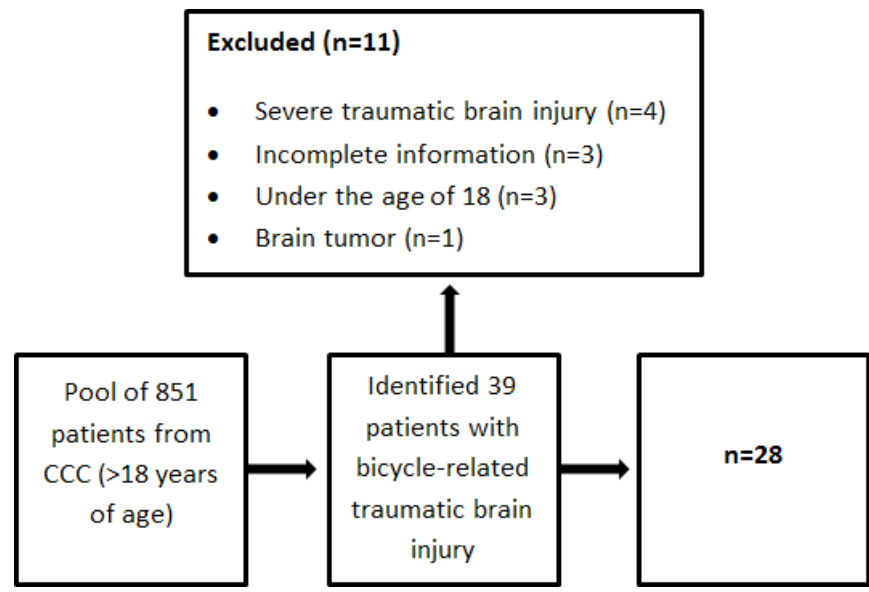

Figure 1 Exclusion criteria for study group $(n=28)$. CCC, Canadian Concussion Centre.

radiographic findings, injury mechanisms, symptomatology and recovery. The information collected was treated confidentially and was deidentified to protect the identities of the patients. The independent variables were patient characteristics and injury mechanism. The dependent variables were the duration of symptoms and the number of persistent symptoms from the most recent bicycling-related concussion. In all cases, the concussion which brought the patient to the CCG was the bicyclingrelated concussion. The information was obtained retrospectively from the clinical data registry and clinical charts of patients followed at the CCC.

\section{Patient and public involvement}

Patients were not involved in defining the research questions, outcome measures or overall design of the study. We plan to involve the bicycling community to disseminate the results of the present study.

\section{Definitions}

A bicyclist was defined as someone who uses a nonmotorised two wheeled vehicle. There were no bicycle motocross or cyclo-cross bicyclists included in the study. A bicycling-related injury was defined as an injury which occurred while the bicyclist was either bicycling or getting on or off a bicycle. A fall was defined as a non-motorised vehicle inflicted injury. Concussion was defined according to the fifth International Conference on Concussion in Sport. ${ }^{23}$ PCS was defined as one or more concussion symptoms which persisted for longer than 3 months. ${ }^{13}$ The diagnosis of PCS was made clinically without the use of any diagnostic tools, as there is no proven biomarker. ${ }^{24}$ Patients were referred to CHT for assessment/treatment of their persistent symptoms. Extracranial injuries were defined as other injuries that occurred at the time of concussion. Persistent symptoms were defined as concussion symptoms experienced by the patients for at least 3 months following the bicycling concussion. The duration of symptoms was identified at the last clinic appointment, and if symptoms were still present, the duration was indicated as the last known 
duration and denoted 'still present'. The treatment offered for PCS was multidisciplinary and symptom oriented for management of headaches, mental health issues, dizziness and other symptoms with an emphasis on exercise and respect for thresholds at which symptom exacerbation occurred.

The collision sports comparison group was composed of 86 adult patients who sustained a concussion playing hockey, football, rugby, Australian rules football and boxing during the same period of time from 2008 to 2018. There were 249 patients in total who sustained a concussion playing these collision sports, but 163 were excluded. The same inclusion and exclusion criteria were used to select the comparison group.

\section{Statistical analysis}

SPSS software (IBM SPSS Statistics V.25.0 for Windows; IBM) was used for statistical analysis. We used descriptive statistics to assess the characteristics of the concussed bicyclists in the study group. The Kruskal-Wallis test was used to measure the relationships of age and the number of previous concussions in relation to the duration of symptoms and the number of PCS symptoms. The data did not follow a normal distribution, and so the Kruskal-Wallis test was used instead of the one-way analysis of variance. Similarly, the Mann-Whitney U test was used instead of the independent-samples t-test to assess sex, the presence of a pre-existing condition, helmet use and concussion mechanism in relation to the duration of symptoms with a $95 \%$ CI. The Mann-Whitney U test was also used to assess differences in sex, the presence of pre-existing conditions, helmet use and duration of symptoms in relation to the number of reported PCS symptoms. For comparison to the collision sports group, normality was assumed and the independent-samples t-test was used to assess differences in sex, mean age, mean number of previous concussions, duration of symptoms and number of persistent symptoms between the bicycling and the collision sports groups. Relative risk (RR) was calculated to compare the incidence of loss of consciousness (LOC) and amnesia. $\mathrm{P}<0.05$ was regarded as statistically significant.

\section{RESULTS}

\section{Patient characteristics}

Table 1 shows the demographic features of the group of 28 cases of adult bicyclists with PCS comprised of 13 males $(46.4 \%)$ and 15 females $(53.6 \%)$. The mean patient age at the time of the bicycling concussion was $42.9 \pm 12.9$, with a median age of 43.5, and a range of 22-71 years of age. Sex and age differences were insignificant for an increased duration of symptoms $(\mathrm{p}=0.96$ and $\mathrm{p}=0.52$, respectively). Sex and age were also insignificant for an increased number of persistent symptoms $(\mathrm{p}=0.59$ and $\mathrm{p}=0.35$, respectively). The mean number of previous concussions was 2.3 with a median of 1.5 . There were 8 patients $(28.6 \%)$ with no previously recorded concussions, 17 patients $(60.7 \%)$ with at least 1 previously
Table 1 Demographic characteristics of the 28 cases of PCS

\begin{tabular}{lll}
\hline Patient characteristics & \\
\hline $\begin{array}{l}\text { Demographic } \\
\text { variable }\end{array}$ & Variable level & n (\% of \\
sample)
\end{tabular}

PCS, postconcussion syndrome.

recorded concussion, and 3 patients $(10.7 \%)$ with at least 8 previously recorded concussions. Patients with one or more previous concussions had a significantly greater duration of symptoms compared with those with no previous concussions $(\mathrm{p}=0.042)$. Patients with one or more previous concussions did not have a greater number of symptoms $(\mathrm{p}=0.967)$. A previous history of migraines or a psychiatric condition was present in 16 patients $(57.1 \%)$ while 12 patients $(42.9 \%)$ had neither of these conditions. Patients with a previous history of migraines or a psychiatric condition (anxiety, depression, attention deficit disorder/attention deficit hyperactivity disorder (ADD/ADHD), and bipolar disorder)) had 
Table 2 The relationship between demographics of bicyclists with PCS (mean duration of 23.7 months) and the duration of symptoms $(n=28)$

\begin{tabular}{|c|c|c|c|c|c|c|c|}
\hline & 3-9m & $10-19 \mathrm{~m}$ & $20-29 m$ & $30-39 m$ & $\geq 40 \mathrm{~m}$ & $\mathbf{N}$ (\% of sample) & $\begin{array}{l}\text { Test } \\
\text { statistic }\end{array}$ \\
\hline n (\% of sample) & $7(25.0)$ & $6(21.4)$ & $7(25.0)$ & $4(14.3)$ & $4(14.3)$ & $28(100.0)$ & \\
\hline Sex, n (\%) & & & & & & & $P=0.96^{\star}$ \\
\hline Male & $4(14.3)$ & $2(7.1)$ & $3(10.7)$ & $1(3.6)$ & $3(10.7)$ & $13(46.4)$ & \\
\hline Female & 3 (10.7) & $4(14.3)$ & $4(14.3)$ & $3(10.7)$ & $1(3.6)$ & 15 (53.6) & \\
\hline $\begin{array}{l}\text { Age at time of concussion, } \\
n(\%)\end{array}$ & & & & & & & $P=0.52 \dagger$ \\
\hline$\leq 29$ & 1 (3.6) & $3(10.7)$ & $0(0.0)$ & $0(0.0)$ & 1 (3.6) & $5(17.9)$ & \\
\hline $30-64$ & $6(21.4)$ & $3(10.7)$ & $7(25.0)$ & $3(10.7)$ & $3(10.7)$ & $22(78.6)$ & \\
\hline$\geq 65$ & $0(0.0)$ & $0(0.0)$ & $0(0.0)$ & $1(3.6)$ & $0(0.0)$ & $1(3.6)$ & \\
\hline Previous concussion, $\mathrm{n}(\%)$ & & & & & & & $P=0.032 \dagger$ \\
\hline 0 & $2(7.1)$ & $4(14.3)$ & $2(7.1)$ & $0(0.0)$ & $0(0.0)$ & $8(28.6)$ & \\
\hline $1-3$ & $4(14.3)$ & $1(3.6)$ & $5(17.9)$ & $3(10.7)$ & $2(7.1)$ & $15(53.6)$ & \\
\hline $4-7$ & $0(0.0)$ & $0(0.0)$ & $0(0.0)$ & $0(0.0)$ & $2(7.1)$ & $2(7.1)$ & \\
\hline$\geq 8$ & $1(3.6)$ & $1(3.6)$ & $0(0.0)$ & $1(3.2)$ & $0(0.0)$ & $3(10.7)$ & \\
\hline Pre-existing conditions, n (\%) & & & & & & & $P=0.90^{*}$ \\
\hline Migraines & $2(7.1)$ & $2(7.1)$ & $0(0.0)$ & $1(3.6)$ & $0(0.0)$ & $5(17.9)$ & \\
\hline Anxiety & $0(0.0)$ & $1(3.6)$ & $1(3.6)$ & $0(0.0)$ & $0(0.0)$ & $2(7.1)$ & \\
\hline Depression & $0(0.0)$ & $1(3.6)$ & $0(0.0)$ & $0(0.0)$ & $0(0.0)$ & $1(3.6)$ & \\
\hline ADD/ADHD & $0(0.0)$ & $1(3.6)$ & $1(3.6)$ & $0(0.0)$ & $0(0.0)$ & $2(7.1)$ & \\
\hline Bipolar disorder & $0(0.0)$ & $0(0.0)$ & $0(0.0)$ & $1(3.6)$ & $0(0.0)$ & $1(3.6)$ & \\
\hline Multiple comorbidities & $1(3.6)$ & $0(0.0)$ & $1(3.6)$ & $1(3.6)$ & $2(7.1)$ & $5(17.9)$ & \\
\hline None & $4(14.3)$ & $1(3.6)$ & $4(14.3)$ & $1(3.6)$ & $2(7.1)$ & $12(42.9)$ & \\
\hline Helmet use, n (\%) & & & & & & & $\mathrm{P}=0.41^{*}$ \\
\hline Yes & $5(17.9)$ & $4(14.3)$ & $5(17.8)$ & $3(10.7)$ & $3(10.7)$ & $20(71.4)$ & \\
\hline No & $2(7.1)$ & $2(7.1)$ & $2(7.1)$ & $1(3.6)$ & $1(3.6)$ & $8(28.6)$ & \\
\hline
\end{tabular}

*Mann-Whitney U test.

†Kruskal-Wallis $\mathrm{H}$ test.

PCS, postconcussion syndrome.

a significantly greater number of persistent symptoms $(\mathrm{p}=0.05)$, but these patients did not have a significantly greater duration of symptoms $(\mathrm{p}=0.90)$. Refer to table 2 for additional information.

Fourteen patients $(50.0 \%)$ also suffered extracranial injuries at the time of their concussion, with nine patients $(32.1 \%)$ sustaining extracranial fractures. Twenty patients $(71.4 \%), 10$ males and 10 females, were wearing a helmet at the time of the concussion, and 8 were not. There was no significant difference in the duration and number of symptoms between helmeted and non-helmeted patients ( $p=0.41$ and $p=0.69$, respectively). No patients were intoxicated at the time of the bicycling-related concussion. Seven patients $(25.0 \%)$ pursued litigation following their concussion.

\section{Concussion mechanisms and features}

All patients were riding a bicycle or getting on or off a bicycle at the time of their concussions. Ten patients
$(35.7 \%)$ lost control of the bicycle and fell, eight (28.6\%) were struck by a motor vehicle, four patients $(14.3 \%)$ tried to avoid striking a person or animal and lost control, four patients (14.3\%) collided with an object, and two patients $(7.1 \%)$ were injured as a result of a collision with another bicycle. There was no significant difference in the duration of symptoms and the mechanism of the concussion (table 3). The purpose of bicycling was also recorded to better understand the concussion mechanisms. Eight patients $(28.6 \%)$ were riding their bicycle for sports and recreation (six $(21.4 \%)$ were participating in a training ride, two $(7.1 \%)$ were participating in a race), six $(21.4 \%)$ were riding for leisure; five patients $(17.9 \%)$ were commuting and in nine $(32.1 \%)$ the purpose of the bicycling trip was unknown. Twenty-seven (96.4\%) patients were road cycling, and one (3.6\%) was mountain biking at the time of the bicycling concussion. All competitionrelated concussions (participating in a training ride/ 
Table 3 The relationship between mechanism of concussion and duration of symptoms (mean duration of 23.7 months) $(n=28)$

\begin{tabular}{|c|c|c|c|c|c|c|c|}
\hline & $3-9 m$ & $10-19 \mathrm{~m}$ & $20-29 m$ & $30-39 \mathrm{~m}$ & $\geq 40 \mathrm{~m}$ & $\mathbf{N}(\%$ of sample) & $\begin{array}{l}\text { Test } \\
\text { statistic }\end{array}$ \\
\hline Motor vehicle crash, n (\%) & $2(7.1)$ & $2(7.1)$ & $2(7.1)$ & $1(3.6)$ & $1(3.6)$ & $8(28.6)$ & $\mathrm{P}=0.93^{*}$ \\
\hline \multicolumn{8}{|l|}{ Fall, $\mathrm{n}(\%)$} \\
\hline Loss of control of bicycle & $3(10.7)$ & $2(7.1)$ & $2(37.1)$ & $1(3.6)$ & $2(7.1)$ & $10(35.7)$ & $\mathrm{P}=0.77^{*}$ \\
\hline Avoided hitting a person/animal & $0(0.0)$ & $2(7.1)$ & $1(3.6)$ & $1(3.6)$ & $0(0.0)$ & $4(14.3)$ & $P=0.86^{*}$ \\
\hline Collision with an object & $1(3.6)$ & $0(0.0)$ & $2(7.1)$ & $0(0.0)$ & $1(3.6)$ & $4(14.3)$ & $P=0.49^{*}$ \\
\hline Bicycle on bicycle accident, $\mathrm{n}(\%)$ & $1(3.6)$ & $0(0.0)$ & $0(0.0)$ & $1(3.6)$ & $0(0.0)$ & $2(7.1)$ & $P=0.65^{*}$ \\
\hline n (\% of sample) & $7(25.0)$ & $6(21.4)$ & $7(25.0)$ & $4(14.3)$ & $4(14.3)$ & $28(100)$ & \\
\hline
\end{tabular}

*Mann-Whitney U test.

race) occurred while the patient was road cycling. Thirteen patients $(46.4 \%)$ experienced amnesia following the bicycling-related concussion and 10 patients $(35.7 \%)$ experienced LOC. There was no significant increase in the duration or number of symptoms in those patients that experienced LOC ( $\mathrm{p}=0.13$ and $\mathrm{p}=0.06$, respectively). Amnesia did not lead to an increased duration of PCS or an increased number of symptoms $(\mathrm{p}=0.26$ and $\mathrm{p}=0.44$, respectively).

\section{Duration of PCS and recovery from PCS}

The mean duration of PCS was 23.7 months, the median was 24 months and the range was 3-85 months (table 2). For males, the mean and median duration was 26.5 and 24 months, with a range of 3 to 85 months, and for females, the mean and median duration was 21.3 and 27 months, with a range of 5-43 months. There was no significant difference in duration of PCS between males and females $(\mathrm{p}=0.96)$. The mean duration of PCS for helmet wearers was 22.9 months, and 16.8 months for patients not wearing a helmet at the time of concussion $(\mathrm{p}=0.41)$. In 15 patients $(53.6 \%)$, the duration of PCS exceeded 2 years. The mean duration of PCS for patients with 0 previous concussions was 13 months. At the time of the last follow-up appointment, only five patients (17.9\%) had recovered completely, and $23(82.1 \%)$ had failed to recover completely and had persisting symptoms. The mean follow-up time for the 28 patients was 17.1 months with a range of 0-73 months. The follow-up time was 0 months for three patients because they did not return for a follow-up appointment.

\section{Radiographic findings}

After the bicycling-related concussion, 23 patients $(82.1 \%)$ had an MRI, one patient $(3.6 \%)$ had a CT scan only, one patient $(3.6 \%)$ had an MRI before the bicyclingrelated concussion and three patients $(10.7 \%)$ had no radiographic study because they were assessed at the CCC before the protocol of recommending MRIs for all PCS patients was implemented (to rule out more serious brain injury or other neurological condition in patients with persisting symptoms). None of the imaging for the included patients showed any brain lesions indicating an injury of greater severity than concussion.

\section{Number and type of PCS symptoms}

The mean number of PCS symptoms was 8 ; the median was 7 , with patients reporting a range of 2-21 persisting symptoms. For females, the mean and median number of PCS symptoms was 7.9 and 7, with a range of $2-15$ symptoms. For males, the mean and median number of PCS symptoms 7.5 and 6 with a range of 2-21 symptoms with no significant difference between males and females $(p=0.59)$. Age differences were insignificant for an increased number of symptoms $(p=0.35)$. The mean number of persistent symptoms for patients who recovered completely was 4.2 , and for patients who had not recovered it was 8.5 . Indeed, $8(28.6 \%)$ non-recovered patients reported $>10$ persistent symptoms $(\mathrm{p}=0.03)$ (table 4). The most prevalent symptoms were headache $(71.4 \%)$, fatigue $(53.6 \%)$, memory problems $(50.0 \%)$, sleep disturbance $(50.0 \%)$, anxiety $(46.4 \%)$ and sensitivity to light/noise $(46.4 \%)$. Of the 10 most prevalent persistent symptoms, six were somatic symptoms (figure 2).

\section{DISCUSSION}

Though the majority of concussions resolve within a month, a significant percentage of patients develop PCS and continue to suffer from their symptoms for a prolonged period of time. ${ }^{12}$ The present study is unique because it provides detailed information about the demographic features, injury mechanism, radiographic findings, persistent symptoms and recovery potential of 28 adults with concussions and PCS from bicycling.

\section{Helmet use in bicycling-related concussions and PCS}

It was interesting to note that the bicyclists with PCS were older than the other groups of PCS patients from the CCC we previously reported. ${ }^{20} 2125$ The bicyclists had a median age 43.5 , and $82.1 \%$ patients were $\geq 30$ years of age. This is of special concern because in three Canadian provinces-Ontario, Manitoba and Alberta-legislation regarding helmet use states that helmet use is mandatory 
Table 4 The relationship between characteristics of bicyclists with PCS and the number of PCS symptoms ( $\mathrm{n}=28$ )

\begin{tabular}{|c|c|c|c|c|c|c|}
\hline & $1-3$ & $4-6$ & $7-9$ & $10+$ & $\mathbf{N}$ (\% of sample) & $\begin{array}{l}\text { Test } \\
\text { statistic }\end{array}$ \\
\hline n (\% of sample) & $4(14.3)$ & $9(32.1)$ & $7(25.0)$ & $8(28.6)$ & $28(100.0)$ & \\
\hline Sex, n (\%) & & & & & & $P=0.59^{*}$ \\
\hline Male & $2(7.1)$ & $5(17.9)$ & $3(10.7)$ & $3(10.7)$ & $13(46.4)$ & \\
\hline Female & $2(7.1)$ & $4(14.3)$ & $4(14.3)$ & $5(17.9)$ & $15(53.6)$ & \\
\hline $\begin{array}{l}\text { Age at time of concussion, } \\
n(\%)\end{array}$ & & & & & & $P=0.35 \dagger$ \\
\hline$\leq 29$ & $0(0.0)$ & $3(10.7)$ & $1(3.6)$ & $1(3.6)$ & $5(17.9)$ & \\
\hline $30-64$ & $3(10.7)$ & $6(21.4)$ & $6(21.4)$ & $7(25.0)$ & $22(78.6)$ & \\
\hline$\geq 65$ & $1(3.6)$ & $0(0.0)$ & $0(0.0)$ & $0(0.0)$ & $1(3.6)$ & \\
\hline Previous concussion, $\mathrm{n}(\%)$ & & & & & & $P=0.06 \dagger$ \\
\hline 0 & $1(3.6)$ & $2(7.1)$ & $2(7.1)$ & $3(10.7)$ & $8(28.6)$ & \\
\hline $1-3$ & $2(7.1)$ & $7(25.0)$ & $4(14.3)$ & $2(7.1)$ & $15(53.6)$ & \\
\hline $4-7$ & $0(0.0)$ & $0(0.0)$ & $1(3.6)$ & $1(3.6)$ & $2(7.1)$ & \\
\hline$\geq 8$ & $0(0.0)$ & $0(0.0)$ & $1(3.6)$ & $2(7.1)$ & $3(10.7)$ & \\
\hline Pre-existing conditions, n (\%) & & & & & & $\mathrm{P}=0.05^{\star}$ \\
\hline Migraines & $0(0.0)$ & $1(3.6)$ & $2(7.1)$ & $2(7.1)$ & $5(17.9)$ & \\
\hline Anxiety & $0(0.0)$ & $0(0.0)$ & $1(3.6)$ & $1(3.6)$ & $2(7.1)$ & \\
\hline Depression & $0(0.0)$ & $0(0.0)$ & $1(3.6)$ & $0(0.0)$ & $1(3.6)$ & \\
\hline ADD/ADHD & $0(0.0)$ & $0(0.0)$ & $2(7.1)$ & $0(0.0)$ & $2(7.1)$ & \\
\hline Bipolar disorder & $0(0.0)$ & $1(3.6)$ & $0(0.0)$ & $0(0.0)$ & $1(3.6)$ & \\
\hline Multiple comorbidities & $0(0.0)$ & $1(3.6)$ & $2(7.1)$ & $2(7.1)$ & $5(17.9)$ & \\
\hline None & $4(14.3)$ & $1(3.6)$ & $4(14.3)$ & $1(3.6)$ & $12(42.9)$ & \\
\hline Helmet use, n (\%) & & & & & & $\mathrm{P}=0.69^{\star}$ \\
\hline Yes & $3(10.7)$ & $8(28.6)$ & $3(10.7)$ & $6(21.4)$ & $20(71.4)$ & \\
\hline No & $1(3.6)$ & $1(3.6)$ & $4(14.3)$ & $2(10.7)$ & $8(28.6)$ & \\
\hline Recovery status, n (\%) & & & & & & $P=0.03^{*}$ \\
\hline Recovered & $2(7.1)$ & $2(7.1)$ & $1(3.6)$ & $0(0.0)$ & $5(17.9)$ & \\
\hline Not recovered & $2(7.1)$ & $7(25.0)$ & $6(21.4)$ & $8(28.6)$ & 23 (82.1) & \\
\hline
\end{tabular}

*Mann-Whitney U test.

†Kruskal-Wallis $\mathrm{H}$ test.

PCS, postconcussion syndrome.

exclusively for youth. According to Carpenter and Warman, only $18 \%$ of Canadians currently live in the provinces that have adopted an all-age helmet law (British Columbia, New Brunswick, Newfoundland and Labrador, Nova Scotia, Prince Edward Island) while $47 \%$ live in provinces with a youth-only helmet law (Alberta, Manitoba, Ontario), and $35 \%$ live in provinces/territories where helmet use is not mandatory for any age groups (Northwest Territories, Nunavut, Quebec, Saskatchewan and Yukon). ${ }^{26}$ Although we found no significant difference in duration of PCS between the 20 helmeted and the 8 unhelmeted bicyclists $(p=0.41)$, it is important to consider that while helmet use cannot prevent concussions, helmet use can reduce the risk of more serious brain injury and skull fracture. Daneshvar et al found that helmet use decreases the potential for severe brain injury, but not for concussion. ${ }^{27}$ Thus, we encourage the implementation of all-age helmet laws in all Canadian provinces, in addition to educational programs and resources for older bicyclists regarding the importance of helmet use in preventing serious head injury.

\section{Previous concussions and symptom duration}

We found that patients with one or more previous concussions had a greater duration of symptoms compared with those with no previous concussions $(p=0.042)$. This is consistent with our previous study showing those with previous concussions have a longer recovery period. ${ }^{24}$ Covassin et al also found that athletes with previous concussions took longer to recover compared with those without a concussion history. ${ }^{28}$ Consequently, it is recommended that individuals who are recovering from a 
Percentage of Patients with Persistent Symptoms

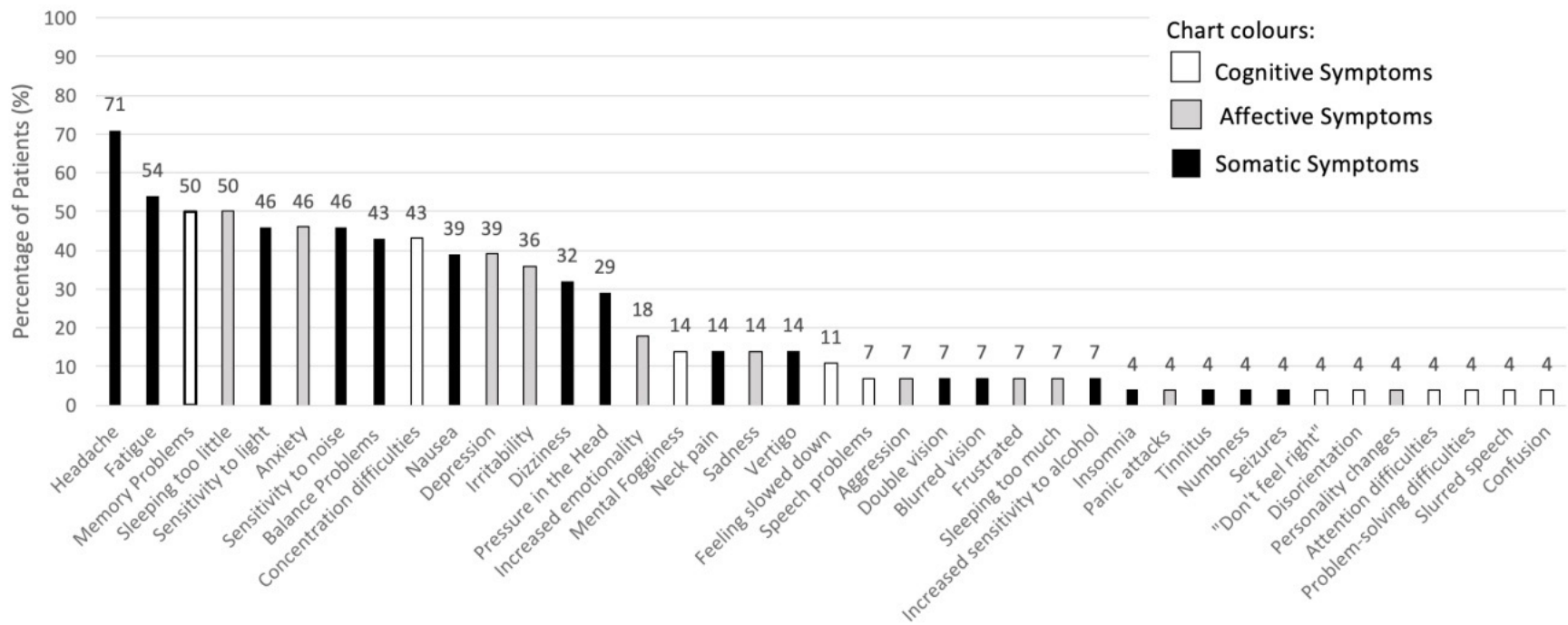

Figure 2 Postconcussion symptoms at least 3 months following the bicycling incident $(n=28)$.

concussion or experiencing PCS should follow current guidelines for return to sports and activities. To avoid a potential subsequent concussion, it is critical that full activity levels are not resumed immediately, but rather that a gradual approach is followed. Individuals should first engage in light aerobic exercise such as stationary bicycling, to prevent exacerbating symptoms, and should not immediately return to road cycling or mountain biking. ${ }^{29}$ Aerobic exercise has been shown to be an effective treatment for many PCS symptoms and may be safely performed by PCS patients. It is important to recognise symptom thresholds, and to not exacerbate symptoms extensively as the optimal timing and dosage of aerobic exercise has not yet been determined. ${ }^{30-32}$

\section{Comorbidities and symptom manifestation}

Additionally, we found that patients with a previous history of migraine or psychiatric disorder had a greater number of persistent symptoms compared with those with no such history $(\mathrm{p}=0.05)$. It is likely that these patients are at risk of having their previous symptoms reappear when they develop PCS. The possibility of a carryover of symptoms between pre-existing migraine or psychiatric disorders and PCS must, therefore, be considered as a potential confounding factor.

\section{Bicycling infrastructure}

In our study population, the most prevalent concussion mechanisms were loss of control of the bicycle, rapid change of direction to avoid hitting a person/animal and collision with an object. Thus, we emphasise the importance of maintaining low to moderate speeds while bicycling. The implementation of improved bicycling infrastructure such as bicycle lanes separated from pedestrians and vehicles is also encouraged to reduce the rate of bicycle collisions, the severity of injury and the RRs of injury. ${ }^{33}$ In the present study, we estimate that bicycle lanes could have prevented the concussion in eight patients $(28.6 \%)$ who were cut-off by a vehicle, hit by a vehicle door or side swiped by a passing vehicle, all of which could have been avoided if the bicyclist was travelling in a bicycle lane. Bicycle lanes have been shown to address several public health issues by reducing injury and death among bicyclists and promoting exercise. ${ }^{35}$ Specifically, $\mathrm{Gu}$ et al report that the construction of $70 \mathrm{~km}$ of bicycle lanes in New York City in 2015 yielded a cost-effectiveness of \$C1398 per quality-adjusted life years gained, costing a total of $\$ \mathrm{C} 10.8$ million. ${ }^{35}$ Parachute Canada reported that the costs accrued for injury to bicyclists in Canada totalled \$C506 million in 2012. ${ }^{14}$ Considering that head injuries contribute to approximately $30 \%$ of admissions to the hospital for bicycling-related injuries and over $75 \%$ of cycling deaths, the societal cost of head injury to bicyclists is considerable. ${ }^{4}$ Therefore, we support the implementation of bicycle lanes in major Canadian cities to protect at-risk bicyclists and reduce the costs of bicycling-related injury.

\section{Number of symptoms and potential for recovery}

The most common symptoms in the 28 bicyclists with PCS were headaches, fatigue and memory problems. We found a significant difference in the number of reported PCS symptoms between the non-recovered patients and patients who eventually recovered $(\mathrm{p}=0.03)$. Recovered and non-recovered patients reported an average of 4.2 and 8.5 symptoms, respectively, with $8(28.6 \%)$ nonrecovered patients reporting $>10$ PCS symptoms. This clearly indicates a relationship between number of PCS symptoms and recovery potential, and is consistent with our previous study which showed that the number of reported PCS symptoms was significantly associated with time to recovery. ${ }^{25}$ 
Table 5 Demographic and PCS characteristics of the collision sports comparison group

Bicycling group $(n=28)$ Collision sports group $(n=86)$ Test statistic

\begin{tabular}{|c|c|c|c|}
\hline Mean age (range) $\pm \mathrm{SD}$ & $42.9(22-71) \pm 12.9$ & $25.3(18-58) \pm 8.5$ & $\mathrm{P}=0.00001^{*}$ \\
\hline $\operatorname{Sex}(\%)$ & 13 (46.4) Males & 66 (76.7) Males & $\mathrm{P}=0.025 \dagger$ \\
\hline LOC (\%) & $10(35.7)$ & $6(6.9)$ & $\begin{array}{l}R R=5.1 \ddagger \\
p=0.0005\end{array}$ \\
\hline Amnesia (\%) & $13(46.4)$ & $16(18.6)$ & $\begin{array}{l}R R=2.4 \ddagger \\
p=0.002\end{array}$ \\
\hline Mean duration of PCS (range) & 23.7 months (3-85) & 16.1 months $(3-150)$ & $P=0.07^{*}$ \\
\hline Mean no of persistent symptoms (range) & $8(2-21)$ & $6(1-16)$ & $P=0.19^{*}$ \\
\hline
\end{tabular}

*Independent sample's t-test.

$\dagger X^{2}$ analysis.

IRR ratio.

LOC, loss of consciousness; PCS, postconcussion syndrome; RR, relative risk.

\section{Concussions and PCS in a collision sport comparison group}

To assess the relative severity of the concussions and PCS in bicycling, we examined a comparison group of adult patients with concussions and PCS from collision sports referred to the CCC during the same period of time. The comparison group was composed of 86 patients selected from a group of 249 patients who sustained a concussion while playing the following collision sports: hockey, football, rugby, Australian Rules football and boxing. These 86 patients were included because they were $\geq 18$ years of age and had normal radiographic findings (table 5). Age and sex differences between the bicycling and comparison groups were statistically significant $(\mathrm{p}=0.00001$ and $\mathrm{p}=0.025$, respectively). However, age and sex differences were found to be insignificant with respect to duration and number of symptoms, and thus, these demographic differences between the two groups may not affect the validity of the analysis of differences between PCS in bicyclists and PCS in other collision sports. It was interesting to note that the RR of sustaining LOC in bicycling compared with the collision sports was 5.1 indicating that the bicycling group was 5.1 times and $410 \%$ more likely to experience LOC. Furthermore, the RR of experiencing amnesia from a bicycling concussion compared with a collision sports concussion was 2.4, indicating that the bicycling group was 2.4 times and 140\% more likely to experience amnesia following their concussion. In addition, the mean duration of PCS in the bicycling group was 23.7 vs 16.1 months in the collision sports groups $(\mathrm{p}=0.07)$. These findings emphasise the severity of bicycling concussions and the need for safe bicycling practices. The authors predict that the speed at which bicyclists travel and the height from which they fall may contribute to the increased risk of sustaining LOC and amnesia while bicycling compared with collision sports.

The persistence of PCS can restrict the ability to return to school, work or play and lead to feelings of frustration and helplessness due to the paucity of proven treatments for PCS. ${ }^{25}$ It is therefore of paramount importance that bicyclists practice injury prevention when bicycling, such as yielding to pedestrians and vehicles on the road.

\section{Limitations}

The limitations of this study include the small sample size of adult patients managed at one tertiary medical centre. Thus, the findings observed in this study may not be representative of the entire adult bicyclist population in Canada. The small sample size also decreased the statistical power of the study, which may have increased the probability of a type II error. Furthermore, all studies of PCS are based on clinical criteria due to the lack of proven biomarkers based on blood tests, imaging or computerised neuropsychological screening. Also, our study included patients with pre-existing morbidities, such as anxiety or depression which have overlapping symptoms with PCS, and so some symptoms may not have arisen solely from the concussion, but rather from pre-existing conditions. Furthermore, the persistent symptoms described by the patients were self-reported, and some patients may have been motivated to exaggerate the duration of symptoms for secondary gain such as enhanced success in litigation. Lastly, data regarding the results of specific treatments was not collected for this study, but would have been useful in elucidating recovery for the patients included.

\section{CONCLUSIONS}

We evaluated the epidemiological factors that correlate with the development of PCS in adult patients following concussions sustained in bicycling. The median age was 43.5 years and $82.1 \%$ were $\geq 30$ years of age. Patients with one or more previous concussions had a significantly greater duration of symptoms than those with no concussion history $(\mathrm{p}=0.042)$. Patients who had failed to recover $(82.1 \%)$ and patients with a previous history of migraine or a psychiatric disorder $(57.1 \%)$ reported a significantly greater number of PCS symptoms $(\mathrm{p}=0.03$ and $\mathrm{p}=0.05$, respectively). Bicycling concussions resulted in a greater duration of PCS (23.7 months) compared with a collision sports comparison group (16.1 months). Also, the bicycling group was 5.1 times more likely to experience LOC and 2.4 times more likely to experience amnesia compared with a collision sports comparison group 
$(\mathrm{p}=0.07)$. The most prevalent concussions mechanisms were loss of control of bicycle, quick manoeuvres to avoid hitting a person/animal and collision with an object. The most common persistent symptoms were headaches, fatigue and memory problems. Brain injury prevention measures suggested by this study include legislation requiring all-age helmet use, addition of bicycling infrastructure and safe bicycling practices such as speed reduction.

Acknowledgements We would like to acknowledge the contribution of Seyed Ali Naeimi for his help with the initial data collection in this study.

Contributors CM: Summer research assistant at the Canadian Concussion Centre, level IV Bachelor of Health Sciences (Honours) student at McMaster University. PB: Summer research assistant at the Canadian Concussion Centre, second-year MSc candidate in medical science at the University of Toronto Institute Of Medical Science. Received a bachelor's degree in Biological Sciences and Psychology (minor) from Ryerson University. MK: Clinical Research Coordinator, Canadian Concussion Centre, Krembil Brain Institute, and Toronto Western Hospital. CHT: Emeritus Scientist, Krembil Brain Institute, Toronto Western Hospital and Professor of Neurosurgery, University of Toronto. CM, PB. MK and CHT conceived and designed the study. CM and PB analysed the data and prepared the first draft of the manuscript. CM, MK and CHT made further contributions in interpreting the data, and revising the manuscript, and have given approval for the final version to be submitted.

Funding Funds for this study were provided by the Canadian Concussion Centre, Krembil Brain Institute, at the Toronto Western Hospital, which is funded by the Toronto General and Western Hospital Foundation.

Competing interests None declared.

Patient and public involvement Patients and/or the public were not involved in the design, or conduct, or reporting, or dissemination plans of this research.

Patient consent for publication Not required.

Ethics approval This study was given ethics approval by the Research Ethics Board of the University Health Network, with the approval ID: 13-6167-BE.

Provenance and peer review Not commissioned; externally peer reviewed.

Data availability statement Data can be made available upon reasonable request. The data used for this study was deidentified participant data. The information collected included patient characteristics (sex, age, previous concussions and pre-existing conditions), helmet use during the bicycling incident radiographic findings, injury mechanisms, symptomatology and recovery. The information collected was treated confidentially and was deidentified to protect the identities of the patients. The independent variables were patient characteristics and injury mechanism. The dependent variables were the duration of symptoms and the number of persistent symptoms from the most recent bicycling-related concussion. In all cases, the concussion which brought the patient to the CCC was the bicycling-related concussion. The information was obtained retrospectively from the clinical data registry and clinical charts of patients followed at the CCC. The data can be retrieved upon reasonable request from CHT at: Charles.Tator@ uhn.ca

Open access This is an open access article distributed in accordance with the Creative Commons Attribution Non Commercial (CC BY-NC 4.0) license, which permits others to distribute, remix, adapt, build upon this work non-commercially, and license their derivative works on different terms, provided the original work is properly cited, appropriate credit is given, any changes made indicated, and the use is non-commercial. See: http://creativecommons.org/licenses/by-nc/4.0/.

ORCID iD

Connor Moore http://orcid.org/0000-0002-7185-851X

\section{REFERENCES}

1 Page JL, Macpherson AK, Middaugh-Bonney T, et al. Prevalence of helmet use by users of bicycles, push scooters, inline skates and skateboards in Toronto and the surrounding area in the absence of comprehensive legislation: an observational study. Inj Prev 2012;18:94-7.
2 Saleh F, Simson H, Tator $\mathrm{CH}$. Catastrophic injuries in sports and Recreation. Causesand prevention. A Canadian study. Toronto (ON: University of Toronto Press, 2008: 371-81.

3 Ramage-Morin PL. Cycling in. Canada: Statistics Canada, 2017. https://www150.statcan.gc.ca/n1/pub/82-003-x/2017004/article/ 14788-eng.htm

4 Dennis J, Potter B, Ramsay T, et al. The effects of provincial bicycle helmet legislation on helmet use and bicycle ridership in Canada. Inj Prev 2010;16:219-24.

5 Iverson GL. Outcome from mild traumatic brain injury. Curr Opin Psychiatry 2005;18:301-17. 2005.

6 Bazarian JJ, Wong T, Harris M, et al. Epidemiology and predictors of post-concussive syndrome after minor head injury in an emergency population. Brain Inj 1999;13:173-89.

7 Jotwani V, Harmon KG. Postconcussion syndrome in athletes. Curr Sports Med Rep 2010;9:21-6.

8 Prigatano GP, Gale SD. The current status of postconcussion syndrome. Curr Opin Psychiatry 2011;24:243-50.

9 Shenton ME, Hamoda HM, Schneiderman JS, et al. A review of magnetic resonance imaging and diffusion tensor imaging findings in mild traumatic brain injury. Brain Imaging Behav 2012;6:137-92.

10 Mittenberg W, Strauman S. Diagnosis of mild head injury and the postconcussion syndrome. J Head Trauma Rehabil 2000;15:783-91.

11 Broshek DK, De Marco AP, Freeman JR. A review of postconcussion syndrome and psychological factors associated with concussion. Brain Inj 2015;29:228-37.

12 Ryan LM, Warden DL. Post concussion syndrome. Int Rev Psychiatry 2003;15:310-6.

13 Ingebrigtsen T, Waterloo K, Marup-Jensen S, et al. Quantification of post-concussion symptoms 3 months after minor head injury in 100 consecutive patients. J Neurol 1998;245:609-12.

14 Parachute. The cost of injury in Canada. Toronto (on): Parachute, 2015. Available: http://www.parachutecanada.org/downloads/ research/Cost_of_Injury-2015.pdf [Accessed 13 May 2019].

15 Vikane E, Hellstrøm T, Røe C, et al. Predictors for return to work in subjects with mild traumatic brain injury. Behav Neurol 2016;2016:1-10.

16 Emanuelson I, Wendt LV, Hagberg I, et al. Early community outreach intervention in children with acquired brain injury. Int $J$ Rehabil Res 2003;26:257-64.

17 Ben Arzi N, Solomon Z, Dekel R. Secondary traumatization among wives of PTSD and post-concussion casualties: distress, caregiver burden and psychological separation. Brain Inj 2000;14:725-36.

$18 \mathrm{Li} \mathrm{G}$, Baker SP, Fowler C, et al. Factors related to the presence of head injury in bicycle-related pediatric trauma patients. J Trauma 1995;38:871-5

19 Park JC, Chang IB, Ahn JH, et al. Epidemiology and risk factors for bicycle-related severe head injury: a single center experience. Korean J Neurotrauma 2017;13:90-5.

20 Depreitere B, Van Lierde C, Maene S, et al. Bicycle-Related head injury: a study of 86 cases. Accid Anal Prev 2004;36:561-7.

21 Tator $\mathrm{CH}$, Davis $\mathrm{H}$. The postconcussion syndrome in sports and recreation: clinical features and demography in 138 athletes. Neurosurgery 2014;75 Suppl 4:106-12.

22 Tator $\mathrm{CH}$, Davis HS, Dufort PA, et al. Postconcussion syndrome: demographics and predictors in 221 patients. J Neurosurg 2016;125:1206-16.

23 McCrory P, Meeuwisse W, Dvořák J, et al. Consensus statement on concussion in sport-the $5^{\text {th }}$ international conference on concussion in sport held in Berlin, October 2016. Br J Sports Med 2017;51:838-47.

24 Tator $\mathrm{CH}$. Concussions and their consequences: current diagnosis, management and prevention. CMAJ 2013;185:975-9.

25 Hiploylee C, Dufort PA, Davis HS, et al. Longitudinal study of postconcussion syndrome: not everyone recovers. J Neurotrauma 2017;34:1511-23.

26 Carpenter CS, Warman C. Do All-Age'Bicycle helmet laws work? Evidence from Canada. National Bureau of Economic Research, 2018.

27 Daneshvar DH, Baugh CM, Nowinski CJ, et al. Helmets and mouth guards: the role of personal equipment in preventing sport-related concussions. Clin Sports Med 2011;30:145-63.

28 Covassin T, Stearne D, Elbin R. Concussion history and postconcussion neurocognitive performance and symptoms in collegiate athletes. J Athl Train 2008:43:119-24.

29 GUIDELINES FOR RETURN TO PLAY AFTER A CONCUSSION. Coach.ca, 2020. Available: https://www.coach.ca/files/returntoplay guidelines.pdf [Accessed 24 Feb 2020].

30 Lal A, Kolakowsky-Hayner SA, Ghajar J, et al. The effect of physical exercise after a concussion: a systematic review and meta-analysis. Am J Sports Med 2018;46:743-52. 
31 Leddy JJ, Haider MN, Ellis M, et al. Exercise is medicine for concussion. Curr Sports Med Rep 2018;17:262-70.

32 Kozlowski KF, Graham J, Leddy JJ, et al. Exercise intolerance in individuals with postconcussion syndrome. J Athl Train 2013;48:627-35.

33 Teschke K, Koehoorn M, Shen $\mathrm{H}$, et al. Bicycling injury hospitalisation rates in Canadian jurisdictions: analyses examining associations with helmet legislation and mode share. BMJ Open 2015;5:e008052.
34 Cripton PA, Shen H, Brubacher JR, et al. Severity of urban cycling injuries and the relationship with personal, trip, route and crash characteristics: analyses using four severity metrics. BMJ Open 2015;5:e006654.

$35 \mathrm{Gu}$ J, Mohit B, Muennig PA. The cost-effectiveness of bike lanes in New York City. Inj Prev 2017;23:239-43. 